\title{
SISTEMAS DE INDICADORES DE SUSTENTABILIDADE EMPRESARIAL PARA O SETOR SUCROENERGÉTICO FOMENTADOS EM PROGRAMAS DE PÓS-GRADUAÇÃO
}

\author{
Josicleide de Amorim Pereira Moreira ${ }^{1}$ \\ Eduardo Rodrigues Viana de Lima ${ }^{2}$ \\ Bruno César Bezerra Nóbrega de Souza ${ }^{3}$
}

Resumo: O objetivo desta pesquisa é identificar os sistemas de indicadores de sustentabilidade empresarial direcionados ao setor sucroenergético. Como objeto de análise, optaram-se pelas produções científicas desenvolvidas no Brasil e disponibilizadas no portal da Biblioteca Digital Brasileira de Teses e Dissertações. Para tanto, considerou-se a Análise de Redes Sociais, adotando-se o grau de centralidade entre os atores da rede social analisada. Os principais resultados foram os seguintes: insuficiência de produções científicas que contemplem, minimamente, as dimensões de sustentabilidade econômica, social e ambiental; produção média de 1,2 trabalhos por ano, entre 2000 e 2019, sem abranger todos os setores econômicos; e um único trabalho direcionado ao setor sucroenergético.

Palavras-chave: Indicadores de Sustentabilidade; Sustentabilidade Empresarial; Setor Sucroenergético.

Abstract: The objective of this research is to identify the systems of corporate sustainability indicators directed to the sugarcane-based bioenergy sector. As object of analysis, we opted for scientific productions developed in Brazil and made available on the Brazilian Digital Library of Theses and Dissertations website. Therefore, the Social Network Analysis was considered, adopting the degree centrality between the actors of the analyzed social network. The main results were the following: insufficient scientific productions that minimally encompass the dimensions of economic, social and environmental sustainability; average production of 1.2 jobs per year, between 2000 and 2019, without covering all economic sectors; and a single work directed to the sugarcane-based bioenergy sector.

Keywords: Sustainability Indicators; Corporate Sustainability; Sugarcane-Based Bioenergy Sector.

${ }^{1}$ Universidade Federal de Alagoas. E-mail: josicleideamorim@gmail.com,

Link para o Lattes: http://lattes.cnpq.br/0236097730602652

2 Universidade Federal da Paraíba. E-mail: eduvianalima@gmail.com,

Link para o Lattes: http://lattes.cnpq.br/2941361024141417

3 Universidade Federal da Paraíba. E-mail: brunocbns@gmail.com,

Link para o Lattes: http://lattes.cnpq.br/8349802944743874

Revbea, São Paulo, V. 17, № 1: 150-171, 2022. 


\section{Introdução}

Os debates em torno das questões ambientais têm se intensificado na medida em que se constatam as externalidades negativas decorrentes das ações antrópicas, cujos efeitos têm repercussões tanto em escala local, como regional e global.

Diante de tais constatações, a sustentabilidade passou a ser discutida por órgãos internacionais e nacionais em busca de soluções para enfrentar o agravamento dos problemas ambientais, resultando, entre outras ações, em acordos diplomáticos que ensejam o desenvolvimento sustentável.

A Comissão Mundial sobre Meio Ambiente e Desenvolvimento ao definir o termo desenvolvimento sustentável, coloca-o, também, como um desafio para a humanidade, tendo em vista o compromisso em ter que suprir suas necessidades atuais sem comprometer o suprimento das necessidades das futuras gerações. Em outras palavras, seria o princípio de garantir que as ações humanas cotidianas não limitem a disponibilidade de uma série de alternativas econômicas, sociais e ambientais para as futuras gerações (ELKINGTON, 2001).

Nesse contexto, pode-se afirmar que não há como dissociar as externalidades decorrentes das atividades humanas, as quais incidem nas vertentes econômica, ambiental, social, cultural, entre outras, uma vez que as mesmas devem se manter compatibilizadas, já que o equilíbrio dessas dimensões é que possibilitará o alcance do desenvolvimento sustentável (SACHS, 2002).

Nessa perspectiva, tem-se que as empresas exercem atividades econômicas que em alguma medida alteram o meio ambiente, cujas externalidades negativas podem ser observadas por meio da poluição da água e do ar, no solo contaminado, no desmatamento das florestas, nas alterações de paisagens, no desequilíbrio dos ecossistemas, na extinção de espécies e habitats, no acúmulo de resíduos agroindustriais, nas alterações climáticas (GOLDEMBERG; VILLANUEVA, 2003; RONQUIM, 2010), entre outros impactos.

Por conta disso, o termo sustentabilidade passou a ser relacionado às atividades empresariais, ensejando fundamentá-las na trilogia que compreende a eficiência econômica, a responsabilidade social e a preservação ambiental (LIMA; CUNHA, 2021).

Desse modo, tem-se que as organizações são convocadas a adotarem em suas práxis ações que miniminizem os impactos negativos decorrentes de suas atividades, considerando, portanto, além das questões econômicas, aquelas de cunhos social, ambiental e cultural, de modo a incorporar os conceitos de desenvolvimento sustentável aos seus negócios.

Assim, dada a importância conferida às questões ambientais e à "consciência coletiva" de que todos são responsáveis por uma convivência 
harmoniosa com o meio ambiente, observa-se nos últimos anos movimentos em busca de melhores práticas que atendam os preceitos do desenvolvimento sustentável, resultando em pressões que levam as entidades, públicas ou privadas, com ou sem fins lucrativos, a adotarem rotinas que evitem ou minimizem as externalidades negativas provenientes de suas atividades.

Em decorrência disso, algumas entidades têm incorporado em suas dinâmicas, práticas organizacionais em alinhamento com as dimensões propostas para o alcance da sustentabilidade. Depreende-se disso, 0 reconhecimento, por parte das organizações, de que suas práticas afetam as relações não apenas com os shareholders (acionistas), mas também com stakeholders (partes interessadas), emergindo a Responsabilidade Social.

Portanto, há uma clara tendência no discurso relacionado à sustentabilidade empresarial, o qual enfatiza que a adoção de medidas sustentáveis promove uma imagem corporativa positiva perante a sociedade, mas, para além disso, tem-se que incorporar os aspectos do desenvolvimento sustentável poderá contribuir para o crescimento dos negócios, por meio de ações como a reutilização de água, reaproveitamento de matéria prima, redução de consumo de energia elétrica, entre outros, que concorrem para reduzir os custos de produção, por exemplo.

Destaca-se que não basta incorporar as dimensões do desenvolvimento sustentável, faz-se necessária a utilização de ferramentas que sirvam para mapear em que medida tais dimensões devem ser adotadas pelas empresas, baseando-se nas atividades que são desenvolvidas por elas, de modo a servirem de referência para monitorar as ações empregadas, bem como para identificar os resultados alcançados e estabelecer novas metas a serem atingidas.

Nesse sentido, Amorim e Cândido (2015) apontam que um dos desafios no processo de construção do desenvolvimento sustentável previsto na Agenda 21 é a utilização de instrumentos de mensuração aptos a estabelecerem direcionadores que posicionem o quanto se espera um ambiente sustentável. Consideram ainda que os indicadores de sustentabilidade são apresentados como ferramentas imprescindíveis em termos de acompanhamento e avaliação do progresso em direção ao desenvolvimento sustentável.

A Agenda 21 é um plano de ação que deve ser adotado globalmente, nacionalmente e localmente, pelas organizações abrangidas no sistema das Nações Unidas, bem como por governos e pela sociedade civil em todas as áreas cuja ação humana impacta o meio ambiente. Ela tem por base a sinergia entre os aspectos ambientais, sociais e econômicos, ensejando a sustentabilidade. Conquanto, para o gerenciamento de seus planos de ações, as empresas têm utilizado instrumentos com vistas a acompanhar e sinalizar a evolução de suas práticas, adotando, para tanto, indicadores que reflitam o desempenho empresarial rumo ao desenvolvimento sustentável. Em face dessa realidade, tem-se que os indicadores são ferramentais que possibilitam o 
acompanhamento das variáveis mais relevantes de interesse, bem como o planejamento de ações que visem melhorar o desempenho organizacional (CALLADO, 2010).

Tem-se que os indicadores são fundamentais para efetivar um sistema de desenvolvimento em bases sustentáveis, por meio da operacionalização de um conjunto de variáveis relevantes para a comunicação de informações, bem como para entender a realidade investigada (MARTINS; CÂNDIDO, 2010).

Ressalta-se que considerando o aspecto dinâmico do desenvolvimento sustentável, faz-se necessário o monitoramento e a avaliação dos esforços empreendidos em torno das múltiplas dimensões da sustentabilidade, de modo a conhecer os avanços alcançados em relação às metas estabelecidas, bem como para fundamentar diretrizes para novas ações a serem realizadas. Assim, constata-se na literatura que os indicadores de sustentabilidade são instrumentos balizadores, avaliativos, informativos e de apoio à tomada de decisão, tornando-se essenciais na dinâmica empresarial, já que auxiliam nas questões relacionadas à sustentabilidade corporativa.

O reconhecimento da importância da adoção de indicadores de sustentabilidade foi expresso na Conferência Rio-92 e consolidado na Agenda 21 , que propõe o desenvolvimento de sistemas para monitorar e avaliar 0 progresso para o desenvolvimento sustentável por meio de indicadores que mensurem as alterações ocorridas nas dimensões econômica, social e ambiental. O marco desse debate se deu no ano de 1996, ocasião em que a Comissão de Desenvolvimento Sustentável (CSD) das Nações Unidas editou o documento Indicators of Sustainable Development: framework and methodologies, também denominado de "Livro Azul", no qual constava um conjunto de indicadores que deveriam ser seguidos pelos países signatários da Agenda $21 \mathrm{com}$ vistas ao desenvolvimento sustentável. Tais indicadores passaram por revisões resultando em nova publicação, no ano de 2000, tendo sido atualizados e apresentados em 2007 por meio da publicação do Indicators of Sustainable Development: guidelines and methodologies (SANTOS; PEIXOTO; XAVIER, 2008; SOUZA, 2018).

Desde então, os indicadores de sustentabilidade são apontados como instrumentos capazes de mensurar o desempenho quanto ao desenvolvimento sustentável, além de constituírem bases de informações que auxiliam na tomada de decisão em termos de futuras ações sustentáveis (VAN BELLEN, 2008).

Com base nisso, pode-se afirmar que os indicadores de sustentabilidade empresarial imprimem importância para todos os tipos de empresas, sobretudo, para aquelas que exercem maiores impactos com suas atividades, como é o caso do setor sucroenergético, cujas externalidades provocam danos desde a fase agrícola até o momento do consumo final. Tais danos podem ser constatados em algumas dimensões, demonstrando-se a necessidade da 
implementação de planos de ações para alcançar o desenvolvimento sustentável.

Ademais, tem-se que se por um lado o setor sucroenergético requer a adoção de ações de mitigação de externalidades negativas, por outro lado, observa-se que a agroindústria canavieira tem contribuído, em certa medida, para a promoção do desenvolvimento sustentável, já que tem produzido produtos menos poluentes e que contribuem para a melhoria das condições ambientais, evidenciando-se a dualidade existente nas ações corporativas. Cabe, portanto, o monitoramento e a avaliação dos esforços empreendidos, de modo a conhecer os progressos alcançados pelo setor em relação à sustentabilidade.

Observa-se que várias pesquisas têm levantado questões acerca da sustentabilidade no contexto das organizações e algumas delas apresentam sistemas ou modelos de indicadores de sustentabilidade que podem auxiliar no monitoramento e na avaliação das ações voltadas ao desenvolvimento sustentável, inclusive, com propostas direcionadas a setores econômicos específicos, considerando os aspectos intrínsecos relacionados com as atividades desenvolvidas.

Assim sendo, esta pesquisa objetivou identificar sistemas de indicadores de sustentabilidade empresarial direcionados ao setor sucroenergético.

Pesquisas dessa natureza podem servir como direcionadoras para soluções de problemas que se apresentam no cotidiano. Para além disso, confere ainda o caráter pedagógico que há na incorporação do conceito de desenvolvimento sustentável no contexto empresarial, já que requer aprendizagem, sensibilização e adesão dos shareholders, dos stakeholders, bem como da academia, que por meio da produção científica, disponibiliza à sociedade instrumentos que podem auxiliar na avaliação das ações de sustentabilidade implementadas no ambiente corporativo, justificando-se, portanto, a sua realização.

Este artigo contempla parte dos resultados da tese de doutorado intitulada de "Sistema de Indicadores de Sustentabilidade Empresarial: uma aplicação no setor sucroenergético da Zona da Mata paraibana", apresentada ao Programa de Pós-graduação em Desenvolvimento e Meio Ambiente, da Universidade Federal da Paraíba.

\section{Método de pesquisa}

Nesta pesquisa, tem-se por objeto de análise as produções científicas sobre indicadores de sustentabilidade empresarial, de modo a identificar aquelas direcionadas ao setor sucroenergético. Optou-se como base para a coleta de dados o portal da Biblioteca Digital Brasileira de Teses e Dissertações. Tal base justifica-se devido o país ser referência mundial para o setor sucroenergético, posicionando-se entre os líderes da produção de açúcar 
e etanol; por dominar todos os estágios produtivos (FLAUSINIO, 2015; SILVA; GARCIA; SILVA, 2010); e por ter inúmeros trabalhos voltados ao desenvolvimento do setor.

A seleção da amostra seguiu as seguintes etapas: (1) Estratégia de busca: elegeram-se os termos "indicadores de sustentabilidade empresarial" OR "indicadores de sustentabilidade corporativa"; "método para avaliação de sustentabilidade corporativa" OR "método para avaliação de sustentabilidade empresarial"; "modelo de mensuração de sustentabilidade empresarial" OR "modelo de mensuração de sustentabilidade corporativa", seja em títulos, resumos ou palavras-chave; (2) Lapso temporal: 2000 a 2019; (3) Critérios de seleção: selecionaram-se dissertações e teses que se propuseram a conceber ou modificar sistemas, modelos ou métodos de indicadores de sustentabilidade empresarial, considerando, minimamente, as dimensões de sustentabilidade propostas pelo Tripple Bottom Line (econômica, social e ambiental); (4) Critérios de exclusão: foram excluídos os trabalhos duplicados nas buscas, aqueles que objetivaram replicar sistemas, modelos ou métodos de indicadores de sustentabilidade empresarial já existentes e/ou os que não consideraram as dimensões de sustentabilidade do Tripple Bottom Line; (5) Variáveis investigadas: ano de defesa; tipo de pós-graduação; área de conhecimento; instituições envolvidas; localização geográfica; palavras-chave; dimensões de sustentabilidade consideradas; setor econômico abrangido; e autores cocitados na amostra; (6) Período de levantamento da amostra: abril de 2020.

A análise dos dados se deu por meio da estatística descritiva e por métodos de bibliometria. Considerou-se a Análise de Redes Sociais, adotandose o grau de centralidade entre os atores da rede social analisada.

Os resultados contemplam: (1) Nuvem de palavras-chave: constituída pelo Wordclouds.com, evidenciando-se a frequência das palavras mais recorrentes; (2) Mapas temáticos: elaborados pelo software Quantum GIS, versão 3.8, que mostrou a distribuição espacial dos trabalhos analisados; (3) Grafo de rede de cocitação: construído pelos softwares UCINET 6 e NetDraw. O primeiro analisa dados de redes sociais, representando a relação disposta entre os atores participantes da rede, e o NetDraw visualiza dados de redes sociais (BORGATTI; EVERETT; FREEMAN, 2002; BORGATTI, 2016); (4) Os demais resultados foram evidenciados em figuras, tabelas e gráficos, que auxiliaram na análise e discussão dos dados.

\section{Resultados e discussão}

Ao longo dos anos, pesquisadores têm se dedicado na busca incessante de conceber indicadores de sustentabilidade que sejam capazes de avaliar o quanto se avançou no que se refere ao desenvolvimento sustentável. Frente a isso, observa-se que, no mesmo sentido, são empreendidos esforços para a concepção desses modelos para o contexto empresarial. Vislumbra-se com tal 
perspectiva a adoção desses instrumentos para o controle, a avaliação e o auxílio na tomada de decisão por parte dos gestores das empresas.

Com base nisso, buscou-se levantar junto à Biblioteca Digital Brasileira de Teses e Dissertações (BDTD), as produções científicas, oriundas dos Programas de Pós-Graduação do país, acerca dos sistemas de indicadores de sustentabilidade empresarial, que consideraram, no mínimo, a integração das dimensões econômica, social e ambiental, dentro de um recorte temporal que compreendeu o período de 2000 a 2019, objetivando-se identificar aqueles direcionados ao setor sucroenergético.

A base para seleção da amostra foi composta por 374 trabalhos, sendo 32 para os termos "método para avaliação de sustentabilidade corporativa" OR "método para avaliação de sustentabilidade empresarial", 115 para "modelo de mensuração de sustentabilidade empresarial" OR "modelo de mensuração de sustentabilidade corporativa" e 227 para "indicadores de sustentabilidade empresarial" OR "indicadores de sustentabilidade corporativa". Após aplicação dos critérios de exclusão, determinou-se a composição final da amostra.

Mediante a isso, foi possível levantar 24 trabalhos científicos que atenderam aos critérios desta pesquisa, cujas defesas ocorreram conforme mostra a linha do tempo a seguir (Figura 1).

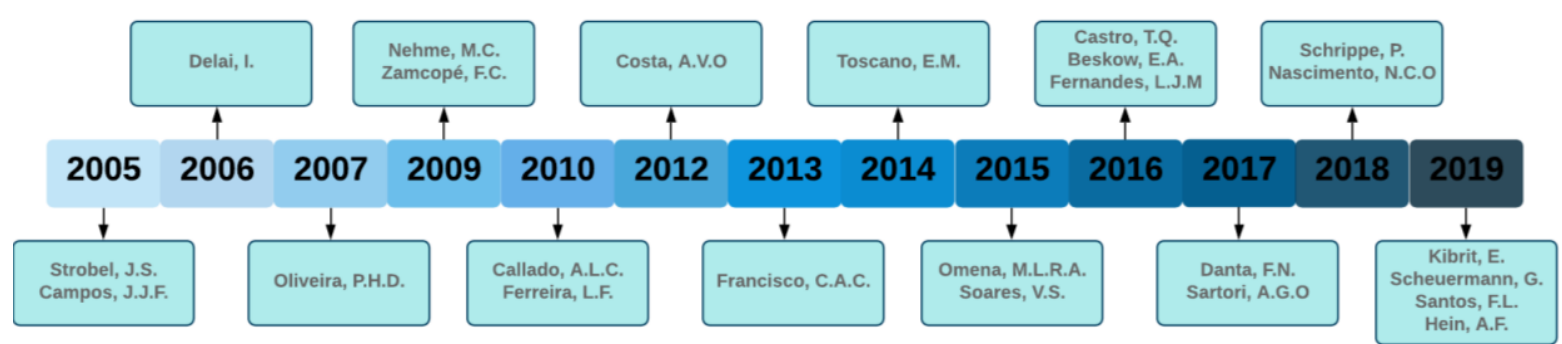

Figura 1: Linha do tempo das pesquisas sobre modelos de indicadores de sustentabilidade empresarial que integraram, minimamente, as dimensões econômica, social e ambiental.

Fonte: Elaborada pela autora, mediante dados da pesquisa, 2020.

Observa-se, por meio da Figura 1, que a distribuição das pesquisas ao longo dos vinte anos não apresenta uma frequência constante, sendo os anos de 2016 e 2019 os de maior volume de produção. Constata-se que 54,2\% desses trabalhos foram defendidos nos últimos cinco anos, evidenciando-se o aumento de interesse pela temática, com a integração das dimensões econômica, social e ambiental.

Silva, Neves e Georges (2018), constataram em sua pesquisa maior incidência de publicações nos anos de 2012 e 2016 no que tange à temática de indicadores de sustentabilidade. Intui-se que tais pesquisas podem ter sido influenciadas por desastres que provocaram relevantes impactos ambientais, a exemplo do ocorrido em 2011, com o vazamento de óleo na Bacia de Campos, Rio de Janeiro, além dos que ocorreram em São Paulo e Minas Gerais, em 2015, representados pelo incêndio nos tanques de combustíveis do Terminal 
Químico de Aratu e pelo rompimento da barragem de Mariana, respectivamente. Contudo, não há dados comprobatórios da influência desses impactos na produção dessas pesquisas.

Verificou-se que as produções científicas da amostra foram desenvolvidas em Programas de Pós-Graduação, sendo 58\% delas em nível de mestrado e os outros $42 \%$ em nível de doutorado (Tabela 1 ).

Tabela 1: Produção científica por Programa de Pós-Graduação.

\begin{tabular}{lcc}
\hline \multicolumn{1}{c}{ Programas de Pós-Graduação } & $\mathrm{N}^{\circ}$ de Produções & Frequência \% \\
\hline Mestrado & 14 & 58 \\
\hline Doutorado & 10 & 42 \\
\hline Total & 24 & 100 \\
\hline
\end{tabular}

Fonte: Elaborada pela autora, mediante dados da pesquisa, 2020.

As grandes áreas de avaliação desses Programas de Pós-Graduação estão classificadas conforme demonstrado no Gráfico 1.

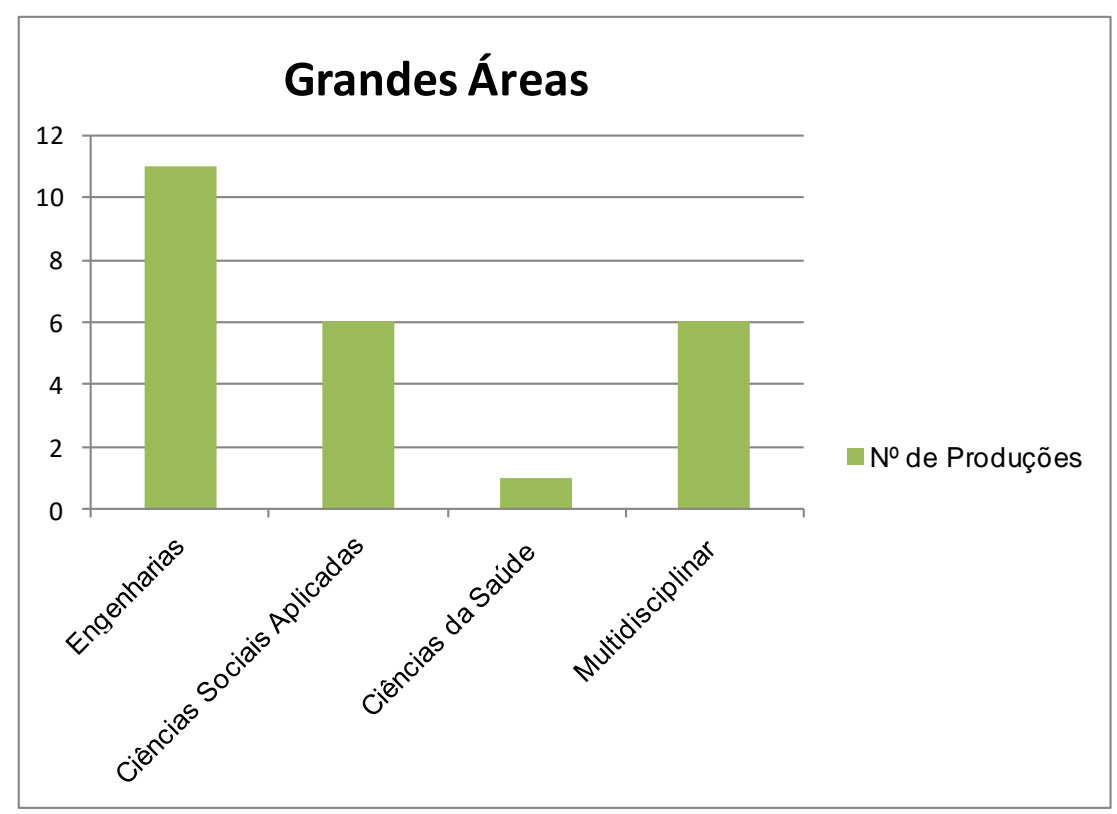

Gráfico 1: Grandes áreas dos Programas de Pós-Graduação participantes da amostra.

Fonte: Elaborado pela autora, mediante dados da pesquisa, 2020.

O Gráfico 1 evidencia que, na amostra analisada, as grandes áreas com produções científicas acerca de Sistema de Indicadores de Sustentabilidade Empresarial são: das Engenharias, com o número de 11 pesquisas, seguida das Ciências Sociais Aplicadas e da Multidisciplinar, que contemplaram 6 
trabalhos em cada uma delas, além das Ciências da Saúde, que apresentou apenas 1 pesquisa nessa temática.

De modo similar, a pesquisa de Silva, Neves e Georges (2018) apontou as áreas das Engenharias e das Ciências Sociais Aplicadas como as de maior ocorrência de produções científicas acerca de indicadores de sustentabilidade. Intui-se que essas áreas concentram o maior número de pesquisas devido à aproximação da temática, tanto quanto aos aspectos produtivos das organizações, como aos de gestão, os quais impactam diretamente nas dimensões de sustentabilidade econômica, social, ambiental, cultural, entre outras.

Os dados da pesquisa revelaram que as produções científicas da amostra deste estudo representam 14 Instituições de Ensino Superior, conforme pode ser observado na Tabela 2.

Tabela 2: Número de produções científicas por instituição de ensino.

\begin{tabular}{lcc}
\hline \multicolumn{1}{c}{ Instituições de Ensino } & $N^{\circ}$ de Produções & Frequência \% \\
\hline Fundação Getúlio Vargas & 1 & 4 \\
\hline Fundação Osvaldo Cruz & 1 & 4 \\
\hline Instituto de Pesquisas Energéticas e Nucleares & 1 & 4 \\
\hline Pontífica Universidade Católica do Rio de Janeiro & 2 & 8 \\
\hline Universidade de Brasília & 1 & 4 \\
\hline Universidade de São Paulo & 2 & 4 \\
\hline Universidade do Vale do Taquari & 1 & 4 \\
\hline Universidade Estadual do Oeste do Paraná & 1 & 4 \\
\hline Universidade Federal da Paraíba & 3 & 17 \\
\hline Universidade Federal de Campina Grande & 1 & 4 \\
\hline Universidade Federal de Santa Catarina & 4 & 8 \\
\hline Universidade Federal de Sergipe & 1 & 13 \\
\hline Universidade Federal do Rio Grande do Norte & 2 & 100 \\
\hline Universidade Federal do Rio Grande do Sul & 3 & 24 \\
\hline Total & 2 & 4 \\
\hline
\end{tabular}

Fonte: Elaborada pela autora, mediante dados da pesquisa, 2020.

Os dados da Tabela 2, mostram que a maioria da produção científica da amostra selecionada, concentra-se na Universidade Federal de Santa Catarina (17\%), na Universidade Federal do Rio Grande do Sul (13\%) e na Universidade Federal da Paraíba (13\%). 
Mediante a tal constatação, foi possível proceder à distribuição espacial dessas pesquisas por Unidade Federativa e Distrito Federal do país. Desse modo, constatou-se que Santa Catarina, Rio Grande do Sul, São Paulo e Paraíba possuem a maioria das produções científicas que atendem aos critérios desta pesquisa, totalizando 16 trabalhos, sendo 4 por Estado. O Rio de Janeiro registrou 3 produções, enquanto o Rio Grande do Norte tem registradas 2 pesquisas. A ocorrência de apenas 1 produção científica no contexto analisado foi observada no Distrito Federal, no Paraná e em Sergipe. Nos demais Estados não houve identificação de trabalhos que atendessem aos critérios estabelecidos.

Por conseguinte, observou-se que a Região Sul lidera as produções científicas investigadas, apresentando um total de 9 trabalhos. Por outro lado, o Sudeste e o Nordeste contabilizam 7 produções científicas em cada uma das Regiões, enquanto a Região Centro-Oeste possui apenas um registro desse tipo de trabalho. Constatou-se ainda a ausência de produções científicas, em consonância com os critérios desta pesquisa, na Região Norte do país, conforme pode ser visualizado na Figura 2.
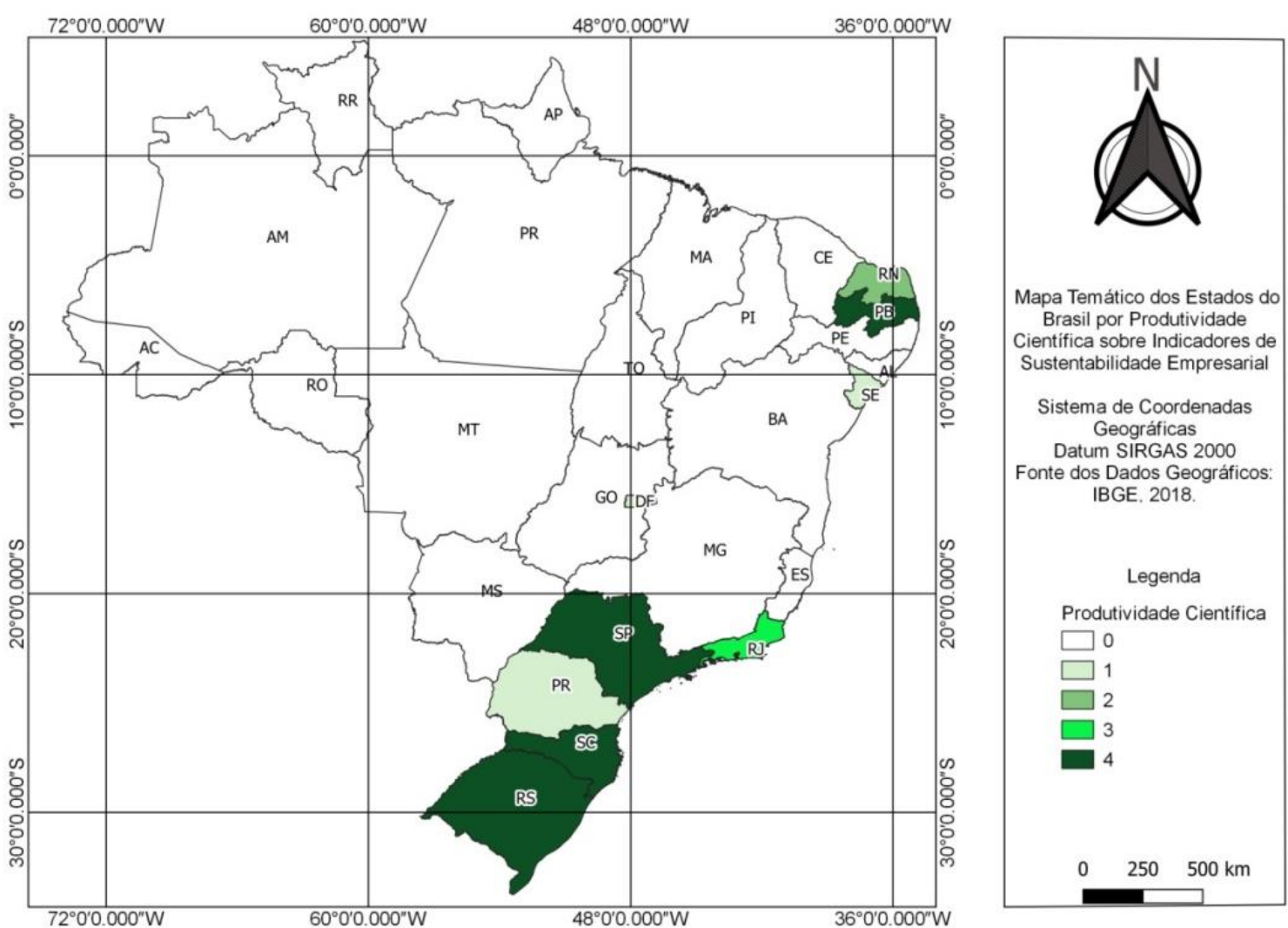

Figura 2: Distribuição espacial das produções científicas sobre indicadores de sustentabilidade empresarial que abrangem, no mínimo, as dimensões econômica, social e ambiental.

Fonte: Elaborado pela autora, mediante dados da pesquisa, 2020 
Tal cenário decorre do fato de que algumas pesquisas em torno de Sistema de Indicadores de Sustentabilidade Empresarial não buscaram integrar, minimamente, as dimensões de sustentabilidade econômica, social e ambiental, conforme prevê a Agenda 21 e os Indicators of Sustainable Development: guidelines and methodologies da Comissão de Desenvolvimento Sustentável (CSD) das Nações Unidas, sendo, portanto, desconsideradas da amostra desta pesquisa.

Verificou-se ainda que as dimensões de sustentabilidade integradas nas produções científicas em análise abrangeram a econômica, econômicofinanceira, ambiental, social, institucional, geral, da natureza do produto, governança corporativa, gestão e governança, e mudanças climáticas.

Pôde-se constatar que as dimensões de sustentabilidade ambiental e social foram consideradas em todas as produções científicas da amostra, e quando somam-se a econômica (21 trabalhos) e a econômico-financeira (3 trabalhos) em uma única dimensão, percebe-se sua ocorrência em todas as produções científicas levantadas. A dimensão institucional foi considerada em 4 trabalhos e as demais dimensões (geral, natureza do produto, governança corporativa, gestão e governança, e mudanças climáticas) foram consideradas em apenas 1 trabalho, cada uma delas, no total de 5 produções científicas participantes da amostra desta pesquisa, conforme mostra o Gráfico 2.

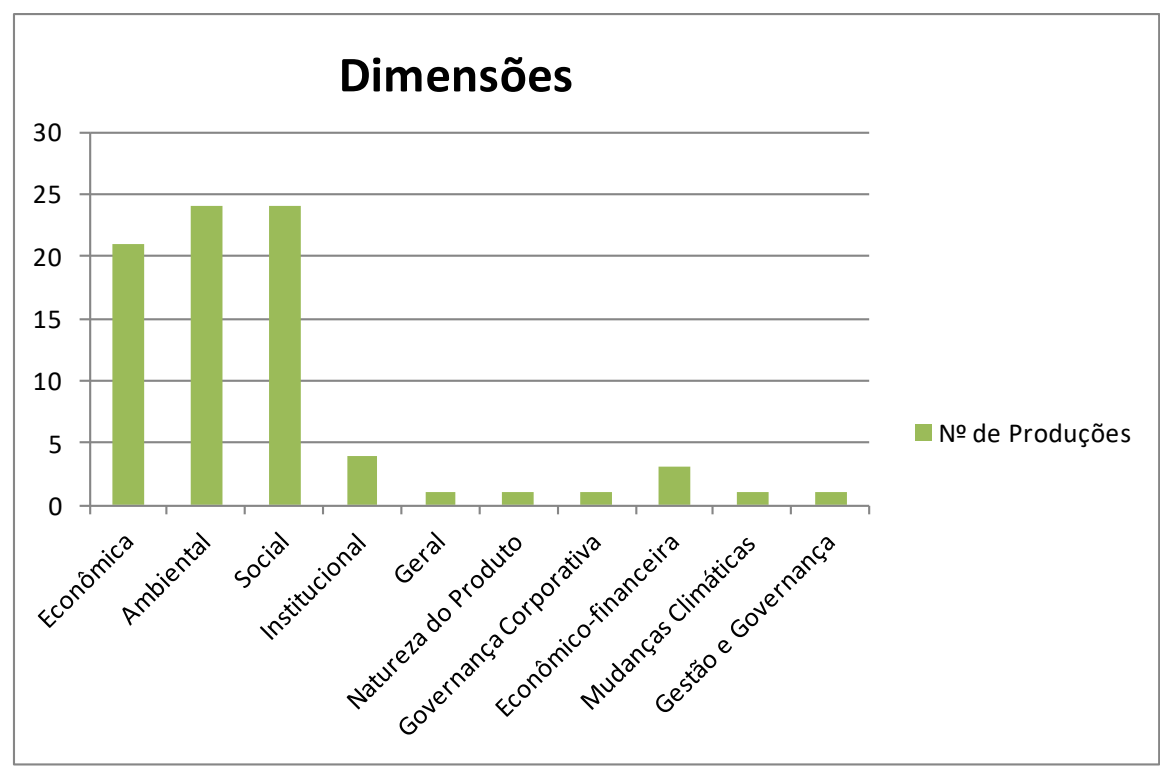

Gráfico 2: Dimensões de sustentabilidade abrangidas nas produções científicas da amostra.

Fonte: Elaborado pela autora, mediante dados da pesquisa, 2020.

Depreende-se, com isso, o consenso entre os pesquisadores da amostra, que consideram na avaliação dos esforços direcionados ao alcance do desenvolvimento sustentável as dimensões econômica, ambiental e social, em consonância com o que prediz a Organisation for Economic Co-operation 
and Development e a Agenda 21, que também mencionam a dimensão institucional (SALDANHA, 2007).

Entende-se, portanto, que o equilíbrio entre tais dimensões se faz necessário, considerando-se que o desenvolvimento econômico deve ter capacidade para atender às necessidades humanas, mas também deve proteger o meio ambiente (ONU MULHERES BRASIL, 2015).

Isso decorre da premissa de que para se avaliar o avanço de uma sociedade não se deve considerar apenas a sua capacidade de gerar riqueza, mas também as condições de se dividir as riquezas geradas e a proteção e conservação do meio ambiente (SANTOS; PEIXOTO; XAVIER, 2008).

Esta pesquisa possibilitou ainda o levantamento das palavras-chave mais recorrentes nas produções científicas da amostra analisada. Desse modo, constatou-se que as palavras-chave mais recorrentes são: sustentabilidade, sustentável, indicadores, desenvolvimento, gestão, desempenho, empresarial e corporativa, conforme mostra a Figura 3.

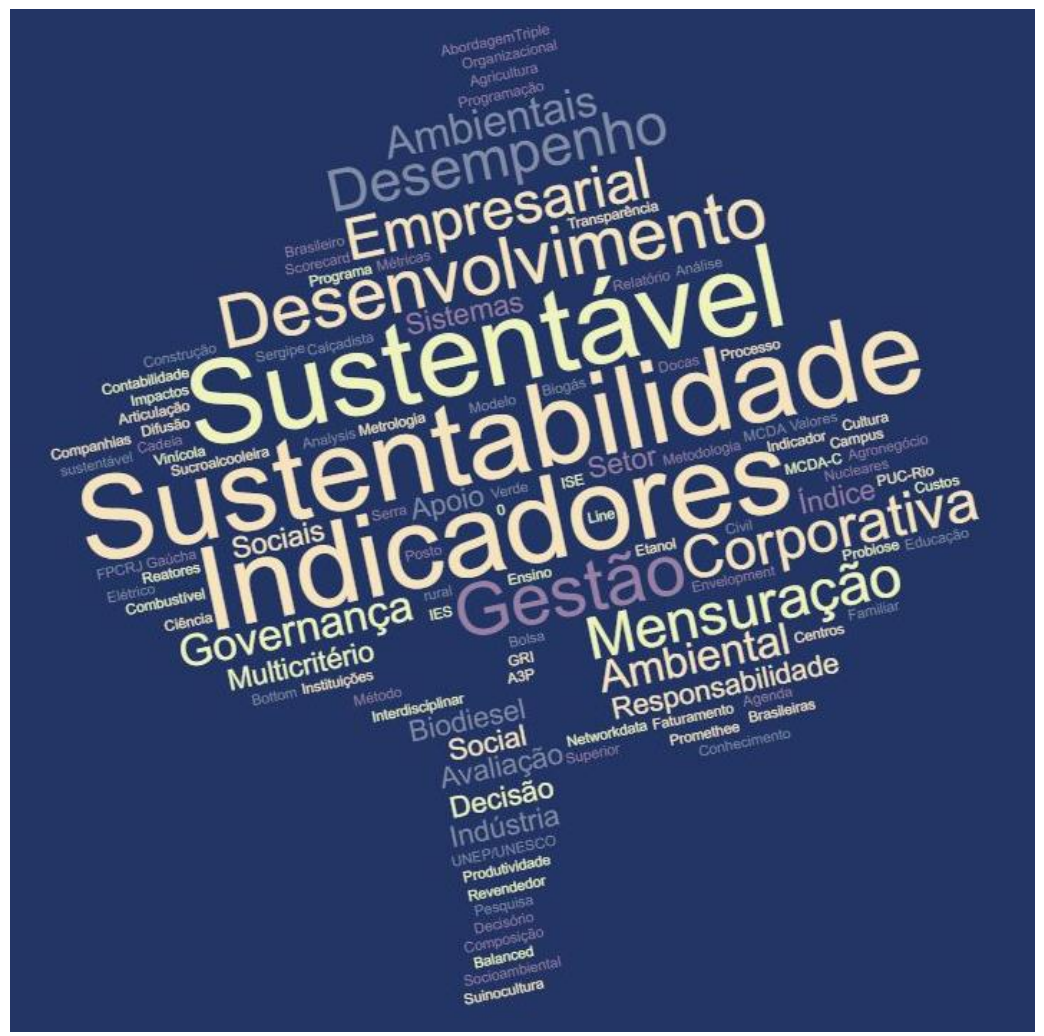

Figura 3: Nuvem de palavras-chave.

Fonte: Elaborada pela autora, mediante dados da pesquisa, 2020

$\mathrm{Na}$ pesquisa desenvolvida por Silva, Neves e Georges (2018), foi construído um mapa de relevância das palavras-chave mais utilizadas nos trabalhos pesquisados, tendo sido identificadas as palavras sustentabilidade, indicadores, sustentável, desenvolvimento e gestão como as mais relevantes. 
É previsível que tais palavras se destaquem em relação às demais, já que existe uma tendência de que as pesquisas que abordam indicadores de sustentabilidade tratem desses temas.

Ademais, levantou-se, por meio da contagem de citações, os autores mais citados nas produções científicas da amostra desta pesquisa, tendo sido selecionados para a elaboração de uma matriz de rede de cocitação aqueles que foram citados, no mínimo, em 5 trabalhos, o que totalizou 31 autores. Somaram-se a esses, os autores das produções científicas que foram cocitados entre si, totalizando 7 autores, que independentemente do número de vezes que foram citados, fazem parte dessa matriz, de modo a demonstrar que tais autores, a partir de suas pesquisas, passaram a ter o reconhecimento e a associação de significados pelos demais autores citados.

Vislumbrando-se destacar os autores cocitados, no texto de discussão dos resultados obtidos nesta pesquisa, optou-se por padronizar a apresentação de seus nomes, destacando-os em letras maiúsculas, ou seja, todos os autores cocitados que fazem parte da amostra deste trabalho têm os seus nomes apresentados na discussão dos resultados desta pesquisa, em letras maiúsculas.

Essa informação se faz necessária para não haver conflito de entendimento entre a padronização adotada neste trabalho e a norma expedida pela Associação Brasileira de Normas Técnicas, ABNT NBR 10520:2002, que dispõe sobre informação e documentação - citações em documentos apresentação.

Dito isso, apresenta-se a Tabela 3 , que elenca os pesquisadores selecionados e o número de produções científicas em que foram citados. Observa-se na Tabela 3 que 55,3\% dos pesquisadores foram citados em mais de 6 produções acadêmicas participantes da amostra deste trabalho, são eles: GRI; VAN BELLEN, H. M.; ELKINGTON, J.; SACHS, I.; HARDI, P.; BOSSEL, H.; ENSSLIN, L.; EPSTEIN, M. J.; HAHN, T.; HART, S. L.; INSTITUTO ETHOS; SCHALTEGGER, S.; WCED; AZAPAGIC, A.; BOFF, L.; GLAVIC, P.; KAPLAN, R. S.; NORTON, D. P.; ONU; SEARCY, C.; WBCSD. Outros $31,6 \%$ dos pesquisadores foram citados, no mínimo, em 5 trabalhos, sendo representados por ALMEIDA, F.; DONAIRE, D.; FIGGE, F.; KRAJNC, D.; MILSTEIN, M. B.; OLIVEIRA, J. H. R.; PORTER, M.; SICHE, R.; TAKAHASHI, S.; VEIGA, J. E.; DELAI, I. e ZAMCOPÉ, F. C., enquanto que $13,1 \%$ foram citados em menos de 5 trabalhos, como é o caso de CALLADO, A. L. C. e STROBEL, J. S., com 4 citações cada um deles, além de CAMPOS, J. J. F.; FERNANDES, L. J. M. e FERREIRA, L. F., com 1 citação cada um deles. Destaca-se que DELAI, I.; ZAMCOPÉ, F. C.; CALLADO, A. L. C.; STROBEL, J. S.; CAMPOS, J. J. F.; FERNANDES, L. J. M. e FERREIRA, L. F. representam o grupo de autores das produções acadêmicas desta pesquisa que foram citados entre os outros autores da mesma amostra, evidenciando o reconhecimento de suas pesquisas entre os seus pares. 
Tabela 3: Pesquisadores e número de produções científicas em que foram citados.

\begin{tabular}{|c|c|}
\hline Pesquisadores & № de produções científicas em que foi citado \\
\hline GRI & 17 \\
\hline VAN BELLEN, H. M. & 15 \\
\hline ELKINGTON, J. & 11 \\
\hline SACHS, I. & 10 \\
\hline HARDI, P. & 8 \\
\hline BOSSEL, H. & 7 \\
\hline ENSSLIN, L. & 7 \\
\hline EPSTEIN, M. J. & 7 \\
\hline HAHN, T. & 7 \\
\hline HART, S. L. & 7 \\
\hline INSTITUTO ETHOS & 7 \\
\hline SCHALTEGGER, S. & 7 \\
\hline WCED & 7 \\
\hline AZAPAGIC, A. & 6 \\
\hline BOFF, L. & 6 \\
\hline GLAVIC, P. & 6 \\
\hline KAPLAN, R. S. & 6 \\
\hline NORTON, D. P. & 6 \\
\hline ONU & 6 \\
\hline SEARCY, C. & 6 \\
\hline WBCSD & 6 \\
\hline ALMEIDA, $\mathrm{F}$. & 5 \\
\hline DONAIRE, D. & 5 \\
\hline FIGGE, F. & 5 \\
\hline KRAJNC, D. & 5 \\
\hline MILSTEIN, M. B. & 5 \\
\hline OLIVEIRA, J. H. R. & 5 \\
\hline PORTER, M. & 5 \\
\hline SICHE, R. & 5 \\
\hline TAKAHASHI, S. & 5 \\
\hline VEIGA, J. E. & 5 \\
\hline DELAI, I. & 5 \\
\hline ZAMCOPÉ, F. C. & 5 \\
\hline CALLADO, A. L. C. & 4 \\
\hline STROBEL, J. S. & 4 \\
\hline CAMPOS, J. J. F. & 1 \\
\hline FERNANDES, L. J. M. & 1 \\
\hline FERREIRA, L. F. & 1 \\
\hline
\end{tabular}

A Figura 4, a seguir, apresenta o grafo de rede de cocitação dos autores mais citados na amostra selecionada. 


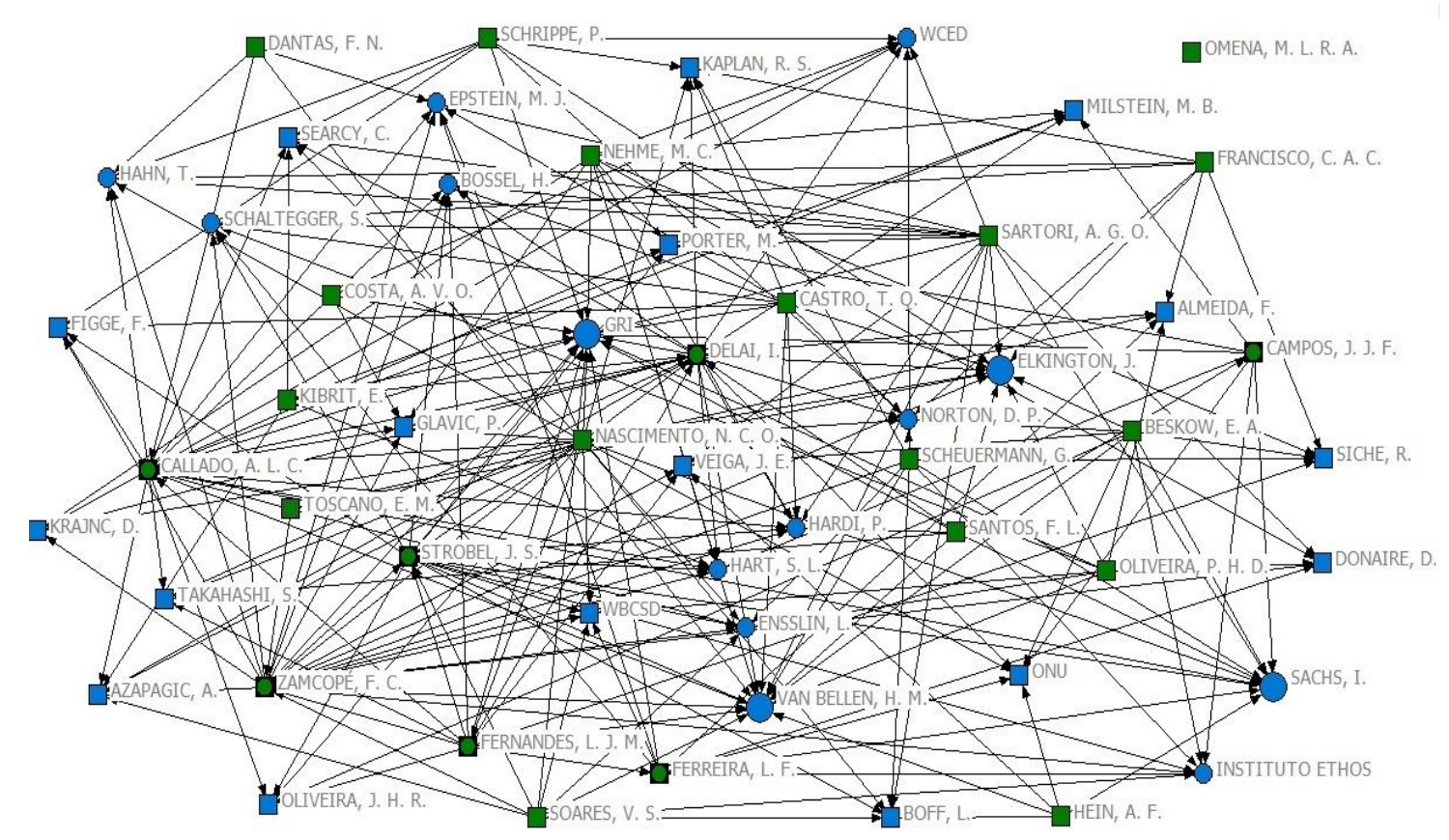

Legenda: $\square$ Autores das produções científicas da amostra; $\boldsymbol{\square}$ Autores das produções científcas que foram citados entre si; $\square$ Cocitados, no mínimo, em 5 produções científicas; O Cocitados entre 6 e 9 produções científicas; Cocitados entre 10 e 17 produções científicas.

Figura 4: Grafo da Rede social de cocitação dos autores mais citados na amostra da pesquisa. Fonte: Elaborado pela autora, mediante dados da pesquisa, 2020.

A Figura 4 representa a rede social de cocitação dos autores mais citados nas produções científicas sobre Sistema de Indicadores de Sustentabilidade Empresarial neste trabalho. Verifica-se que a composição dessa rede se efetivou pela relação entre 55 "atores", sendo que 24 deles representam os autores das produções científicas da amostra desta pesquisa e os outros 31 correspondem, justamente, aos autores que foram citados em mais de cinco dessas produções científicas. Destaca-se que o termo "atores" corresponde às pessoas participantes da rede analisada, ou seja, nesse caso, os autores mais citados nas pesquisas.

É preciso entender que rede social tem sua representação marcada por uma metáfora utilizada na observação dos padrões de conexão existentes em um grupo social, mediante as conexões firmadas entre os variados atores participantes da rede. Sendo assim, sua constituição se dá por meio de nós (vértices) e conexões. Tem-se que os nós representam os atores que formam os grupos, as organizações ou os fenômenos, portanto, trata-se de pessoas participantes da rede em análise, sendo eles os primeiros elementos da rede social. A atuação desses atores molda as estruturas sociais por meio da interação estabelecida entre eles e pela constituição de laços sociais, que são traduzidos em conexões, resultantes das interações que são firmadas entre os "atores" e os seus pares (RECUERO, 2009). 
Assim, têm-se como autores das produções científicas da amostra desta pesquisa: OLIVEIRA, P. H. D.; NEHME, M. C.; COSTA, A. V. O.; FRANCISCO, C. A. C.; TOSCANO, E. M.; OMENA, M. L. R. A.; SOARES, V. S.; CASTRO, T. Q.; BESKOW, E. A.; DANTAS, F. N.; SARTORI, A. G. O.; SCHRIPPE, P.; NASCIMENTO, N. C. O.; KIBRIT, E.; SCHEUERMANN, G.; SANTOS, F. L.; HEIN, A. F., bem como DELAI, I.; ZAMCOPÉ, F. C.; CALLADO, A. L. C.; STROBEL, J. S.; CAMPOS, J. J. F.; FERNANDES, L. J. M. e FERREIRA, L. F., sendo que esses últimos foram citados por alguns de seus pares, como dito anteriormente. Já ALMEIDA, F.; AZAPAGIC, A.; BOFF, L.; BOSSEL, H.; DONAIRE, D.; ELKINGTON, J.; ENSSLIN, L.; EPSTEIN, M. J.; FIGGE, F.; GLAVIC, P.; GRI; HAHN, T.; HARDI, P.; HART, S. L.; INSTITUTO ETHOS; KAPLAN, R. S.; KRAJNC, D.; MILSTEIN, M. B.; NORTON, D. P.; OLIVEIRA, J. H. R.; ONU; PORTER, M.; SACHS, I.; SCHALTEGGER, S.; SEARCY, C.; SICHE, R.; TAKAHASHI, S.; VAN BELLEN, H. M.; VEIGA, J. E.; WBCSD e WCED representam os autores que foram cocitados na amostra desta pesquisa.

$\mathrm{Na}$ Análise de Redes Sociais (ARS), uma das métricas utilizadas é a da centralidade. Optou-se neste trabalho pelo grau de centralidade ou conexão (degree centrality), que mede o número de conexões de um nó (ator), ou seja, o número de setas que um ator da rede possui, evidenciando o grau nodal. Mediante a isso, compreende-se que quanto maior for o número de conexões existentes, mais central será o nó (ator) para a rede (AUTRAN, 2014).

Nesta pesquisa, cada nó representa um autor, tanto das produções científicas da pesquisa, como também daqueles autores mais citados nelas. Por conseguinte, as setas representam as conexões estabelecidas entre eles, as quais foram discriminadas na Tabela 3 e apresentadas na Figura 4. Destaca-se que os nós que aparecem na Figura 4, representados por circunferências maiores, são os que apresentam maior grau de conexão, sendo, portanto, os mais centrais.

Assim, na análise é possível verificar como centralidade da rede alguns nós, com destaque para o que representa a GRI, que obteve o maior grau de conexão na rede, seguido de VAN BELLEN, H. M.; ELKINGTON, J. e SACHS, I., cujos graus de centralidade atingiram os índices 17, 15, 11 e 10, respectivamente.

HARDI, P., obteve o grau de centralidade com índice 8, enquanto que BOSSEL, H.; ENSSLIN, L.; EPSTEIN, M. J.; HAHN, T.; HART, S. L.; INSTITUTO ETHOS; SCHALTEGGER, S. e WCED, atingiram o índice 7. Já AZAPAGIC, A.; BOFF, L.; GLAVIC, P.; KAPLAN, R. S.; NORTON, D. P.; ONU; SEARCY, C. e WBCSD, alcançaram o grau de centralidade com índice 6. Verificou-se ainda que ALMEIDA, F.; DONAIRE, D.; FIGGE, F.; KRAJNC, D.; MILSTEIN, M. B.; OLIVEIRA, J. H. R.; PORTER, M.; SICHE, R.; TAKAHASHI, S.; VEIGA, J. E.; DELAI, I. e ZAMCOPÉ, F. C., tiveram o índice 5, além de CALLADO, A. L. C. e STROBEL, J. S., que obtiveram o grau de centralidade com índice 4. 
Os autores CAMPOS, J. J. F.; FERNANDES, L. J. M. e FERREIRA, L. F. alcançaram o menor grau de centralidade da rede social, cada um tendo atingido $o$ índice 1.

Destaca-se que a Global Reporting Initiative (GRI) trata-se de uma organização internacional independente, precursora nos relatórios de sustentabilidade, tendo como principais produtos os Padrões de Relatórios de Sustentabilidade, gratuitos, para empresas e governos em todo o mundo, representando as melhores práticas globais em termos de relatar questões econômicas, ambientais e sociais, sendo adotados por $93 \%$ das 250 maiores empresas mundiais que relatam desempenho de sustentabilidade (GRI, 2017). Já VAN BELLEN, H. M. tem se destacado por suas contribuições quanto às temáticas de indicadores de sustentabilidade, desenvolvimento sustentável e gestão da sustentabilidade, enquanto ELKINGTON, J. destaca-se por ter concebido o Triple Botton Line, que integra as dimensões ambiental, social e econômica. Por fim, SACHS, I. tem sido recorrente em termos de citações por ter proposto as oito dimensões de desenvolvimento sustentável, sendo elas: social, cultural, ecológica, ambiental, territorial, econômica, política nacional e política internacional.

É preciso entender que os padrões de reconhecimento geram a estrutura da ciência. Logo, quando autores citantes cocitam documentos, atribuem correconhecimento a esses, constituem ainda uma associação de significados, bem como definem as estruturas de suas comunidades (SMALL, 2004), evidenciando o percurso pelo qual o saber científico se concebe e como também se socializa.

Infere-se, com isso, o reconhecimento dos autores das produções científicas da amostra deste trabalho no que tange à centralidade, em termos teóricos, constituída, sobretudo, pelo GRI; por VAN BELLEN, H. M.; ELKINGTON, J. e SACHS, I., já que esses abarcam o maior número de interrelações, posicionando-se como nós centrais da rede, evidenciando-se, com isso, o quão influentes são perante os outros atores da rede social.

Importa destacar que, dentre as 24 produções científicas levantadas, apenas a pesquisadora OMENA, M. L. R. A. não fez uso de citações relacionadas aos 31 autores mais citados da amostra, nem tão pouco citou autores participantes desta pesquisa, tendo, portanto, optado por outra estrutura para o corpo teórico de seu trabalho, ficando desconectada da rede de cocitação, conforme mostra a Figura 4, apresentado anteriormente. Por outro lado, NASCIMENTO, N. C. O. foi o autor que mais fez uso de citações relacionadas aos 31 autores mais citados da amostra, tendo citado 22 deles.

Por fim, foi possível verificar, por meio dos dados da pesquisa, em quais setores econômicos foram aplicados os sistemas de indicadores de sustentabilidade empresarial, concebidos por meio das produções científicas da amostra desta pesquisa. É o que mostra a Tabela 4. 
Tabela 4: Setores de aplicação dos sistemas de indicadores de sustentabilidade empresarial.

\begin{tabular}{|c|c|c|}
\hline Aplicação dos Sistemas por Setores & $\mathrm{N}^{\circ}$ de produções & Frequência \% \\
\hline Têxtil & 3 & 13 \\
\hline Agricultura Familiar & 2 & 8 \\
\hline Indústria Calçadista & 2 & 8 \\
\hline Setor Elétrico & 2 & 8 \\
\hline Biogás & 1 & 4 \\
\hline Centros de Difusão de Ciência, Educação e Cultura & 1 & 4 \\
\hline Construção Civil & 1 & 4 \\
\hline Empresas Listadas na Carteira ISE & 1 & 4 \\
\hline Indústria de Cosméticos & 1 & 4 \\
\hline Instituição de Ensino Superior & 1 & 4 \\
\hline Instituições Públicas & 1 & 4 \\
\hline Micro e Pequenas Agroindústrias & 1 & 4 \\
\hline Operadoras de Reatores Nucleares de Pesquisa & 1 & 4 \\
\hline Postos de Revenda de Combustível & 1 & 4 \\
\hline Produção de Etanol de Cana-de-Açúcar & 1 & 4 \\
\hline Setor Metal Mecânico & 1 & 4 \\
\hline Setor Portuário & 1 & 4 \\
\hline Vinícolas & 1 & 4 \\
\hline Sem Aplicação em Setor Específico & 1 & 4 \\
\hline Total & 24 & 100 \\
\hline
\end{tabular}

Fonte: Elaborada pela autora, mediante dados da pesquisa, 2020.

Os sistemas de indicadores de sustentabilidade empresarial abrangidos nesta pesquisa tiveram o maior número de aplicações no setor têxtil (3 trabalhos), representando $13 \%$ dos trabalhos levantados, seguido dos setores de agricultura familiar (2 trabalhos), indústria calçadista (2 trabalhos) e o elétrico (2 trabalhos). Os demais setores indicados na Tabela 4 foram representados por 1 trabalho cada um deles, com exceção de uma produção científica que não foi aplicada em um setor específico.

Verifica-se que apenas um Sistema de Indicadores de Sustentabilidade Empresarial foi direcionado ao setor sucroenergético. A pesquisa foi desenvolvida por Sartori (2017), tendo sido intitulada como "Produção de indicadores de desempenho em sustentabilidade para o setor de etanol de cana-de-açúcar do estado de São Paulo", cujo objetivo foi o de analisar a publicação de relatórios de sustentabilidade, bem como a suficiência das informações neles publicizadas. Além disso, o autor propôs um conjunto de Princípios, Critérios e Indicadores de desempenho em sustentabilidade direcionado ao campo da produção de etanol oriundo da cana-de-açúcar.

As atividades econômicas exploradas pelo setor sucroenergético constam na lista das Atividades Potencialmente Poluidoras e Utilizadoras de Recursos Ambientais estabelecida pela Instrução Normativa no 06/2013 do Instituto Brasileiro do Meio Ambiente e dos Recursos Naturais Renováveis (IBAMA). Diante disso, requerem maior controle e avaliação de seus impactos, vislumbrando-se mitigar as externalidades negativas provocadas, principalmente, sobre o meio ambiente, mas que por razões diversas atingem 
também a sociedade, necessitando, portanto, de instrumentos que auxiliem em tal avaliação. Tem-se que os sistemas de indicadores de sustentabilidade empresarial atendem a essa perspectiva, desde que eles contemplem as especificidades do setor, englobando todas as atividades produtivas.

Destaca-se que as especificidades inerentes à produção de cada setor requerem métricas que levem em consideração as externalidades que são provocadas de formas peculiares às atividades que estão sendo avaliadas em termos de sustentabilidade, visto que os impactos provocados por cada atividade produtiva são distintos, logo necessitam de modelos de indicadores de sustentabilidade empresarial direcionados a avaliar tais condições.

\section{Conclusão}

Apesar dos avanços relacionados com a temática da sustentabilidade, percebe-se ainda uma lacuna, tendo em vista o número de trabalhos desenvolvidos para avaliar a participação de empresas em ações voltadas para o desenvolvimento sustentável. Intui-se que isso decorre das controvérsias relacionadas ao próprio conceito de desenvolvimento sustentável (FERNANDES; CÂNDIDO, 2015) e pela complexidade na elaboração de modelos que atendam os preceitos inerentes à validação, confiabilidade, integridade, relevância (SALDANHA, 2007) e outros requisitos para tal aferição.

Mediante a isso, fica patente, com base nesta pesquisa, a insuficiência de produções científicas acerca de sistemas de indicadores de sustentabilidade empresarial que contemplem, minimamente, as dimensões de sustentabilidade econômica, social e ambiental. Quanto a isso, os dados da pesquisa revelaram que em vinte anos, em média, 1,2 trabalhos foram produzidos, por ano, nessa perspectiva, sem que tivessem abrangido todos os setores econômicos. Assim, dentro de uma amostra que abrangeu 24 produções científicas, apenas uma delas foi direcionada ao setor sucroenergético, evidenciando-se um exíguo número de sistemas de indicadores de sustentabilidade empresarial voltado ao setor sucroenergético.

Os resultados desta pesquisa apontam ainda as áreas das Engenharias (11 trabalhos), das Ciências Sociais Aplicadas (6 trabalhos) e a Multidisciplinar (6 trabalhos) como as que mais desenvolveram produções científicas relacionadas à sistemas de indicadores de sustentabilidade empresarial, tendo registro de maior quantitativo de produções na Universidade Federal de Santa Catarina (17\%), Universidade Federal do Rio Grande do Sul (13\%) e Universidade Federal da Paraíba (13\%). Além disso, foi possível verificar, por meio da Análise de Redes Sociais, a centralidade dos nós existentes na rede de cocitação dos autores mais citados nas produções científicas sobre Sistema de Indicadores de Sustentabilidade Empresarial, tendo como atores centrais a GRI, cujo grau de centralidade atingiu o índice 17, além de VAN BELLEN, $\mathrm{H}$. M.; ELKINGTON, J. e SACHS, I., que atingiram graus de centralidade correspondente aos índices 15, 11 e 10, respectivamente, sendo, portanto, os 
autores que mais influenciaram na construção de novos conhecimentos nas produções científicas participantes do corpus desta pesquisa.

Evidencia-se, com base nos resultados deste trabalho, a urgente demanda para o desenvolvimento de novas pesquisas que possibilitem operacionalizar modelos capazes de sinalizar o quanto as organizações avançam em relação ao cumprimento das metas para o alcance do staff de empresas sustentáveis, considerando, minimamente, as dimensões econômica, social e ambiental, bem como as especificidades das externalidades atreladas às atividades econômicas, nomeadamente, no contexto desta pesquisa, ao setor sucroenergético, tendo em vista a dualidade dos impactos negativos e positivos decorrentes das atividades produtivas, os quais se refletem no meio ambiente, na sociedade e na economia.

\section{Referências}

AMORIM, B. P.; CÂNDIDO, G. A. Avaliação da sustentabilidade do setor sucroalcooleiro: uma aplicação do barometer of sustainability no município de Pedras de Fogo-PB. Engenharia Ambiental. Espírito Santo do Pinhal, v. 12, n. 1, p. 151-167, jan./jun. 2015.

AUTRAN, M. M. M. Comunicação da ciência, produção científica e rede de colaboração acadêmica: análise dos programas brasileiros de Pós-graduação em Ciência da Informação. 2014. Tese (Doutorado em Informação e Comunicação em Plataformas Digitais) - Universidade do Porto, Faculdade de Letras, $2014 . \quad$ Disponível em: $<$ https://sigarra.up.pt/faup/pt/pub geral.pub view?pi pub base id=34002 $>$.

Acesso em: 06 jun. 2020.

BORGATTI, S. P. Software NetDraw para visualização em rede. Tecnologias analíticas: Lexington, KY, 2016. Disponível em: $<$ https://sites.google.com/site/netdrawsoftware/download>. Acesso em 24 maio 2020.

BORGATTI, S. P; EVERETT, M. G.; FREEMAN, L. C. Ucinet para Windows: Software para análise de redes sociais. Harvard, MA: Tecnologias Analíticas, 2002.

CALLADO, A. L. C. Modelo de mensuração de sustentabilidade empresarial: uma aplicação em vinícolas localizadas na serra gaúcha. 2010. Tese (Doutorado em Agronegócios) - Universidade Federal do Rio Grande do Sul, Porto Alegre, $2010 . \quad$ Disponível em: <https://lume.ufrgs.br/handle/10183/26743>. Acesso em: 20 out. 2019.

ELKINGTON, J. Canibais com garfo e faca. São Paulo: Makron Books, 2001.

FERNANDES, P. A. A.; CÂNDIDO, G. A. Da sustentabilidade à competitividade: um caminho viável? Revista Gestão \& Sustentabilidade Ambiental. Florianópolis, v. 4, n. 1, p. 55-76, abr./set. 2015. 
FLAUSINIO, B. F. P. Produção de energia elétrica a partir do aproveitamento do bagaço de cana-de-açúcar gerado no setor sucroalcooleiro de Minas Gerais. 2015. Tese (Doutorado em Ciências e Técnicas Nucleares) - Universidade Federal de Minas Gerais, Belo Horizonte, 2015. Disponível em: $<$ https://repositorio.ufmg.br/bitstream/1843/BUBD-

AB7FWF/1/tese doutorado cctn bruna flausinio.pdf>. Acesso em: 25 nov. 2019.

GOLDEMBERG, J; VILLANUEVA, L. D. Energia, Meio Ambiente \& Desenvolvimento. São Paulo: Edusp, 2003.

GRI. Sobre a GRI. Amsterdam: GRI, 2017. Disponível em: $<$ https://translate.google.com.br/translate?hl=pt-

BR\&sl=en\&u=https://www.globalreporting.org/\&prev=search>. Acesso em: 30 maio 2020.

LIMA, C. C.; CUNHA, S. C. I. Aplicação do compliance nas empresas de mineração como medida preventiva de danos ambientais. Revista Brasileira de Educação Ambiental, São Paulo, v. 16, n. 2, p. 163-173, 2021.

MARTINS, M. F.; CÂNDIDO. G. A. Índice de desenvolvimento sustentável para localidades: uma proposta metodológica de construção e análise. In: CÂNDIDO, G.A. (org.) Desenvolvimento sustentável e sistemas de indicadores de sustentabilidade: formas de aplicações em contextos geográficos diversos e contingências específicas. Campina Grande: Ed. UFCG, 2010.

ONU MULHERES BRASIL. Cúpula das Nações Unidas sobre o Desenvolvimento Sustentável. Brasília: ONU Mulheres Brasil, 2015. Disponível em: http://www.onumulheres.org.br/noticias/comeca-sexta-feira-25a-cupula-das-nacoes-unidas-sobre-o-desenvolvimento-sustentavel/. Acesso em: 10 jan. 2020.

RECUERO, R. Redes sociais na Internet. Porto Alegre: Sulina, 2009.

RONQUIM, C. C. Queimada na colheita de cana-de-açúcar: impactos ambientais, sociais e econômicos. Campinas: Embrapa Monitoramento por Satélite, 2010.

SACHS, I. Caminhos para o desenvolvimento sustentável. 2. ed. Rio de Janeiro: Garamond, 2002.

SALDANHA, E. E. Modelo de avaliação da sustentabilidade socioambiental. 2007. Tese (Doutorado em Engenharia de Produção) - Universidade Federal de Santa Catarina, Florianópoles, 2007. Disponível em: https://repositorio.ufsc.br/xmlui/bitstream/handle/123456789/90499/240831.pdf? sequence=1\&isAllowed=y. Acesso em 26 nov. 2019. 
SANTOS, M. F. R. F.; PEIXOTO, J. A. A.; XAVIER, L. S. Indicadores de desenvolvimento sustentável: estudo comparativo entre Brasil e Suíça. Revista Pensamento Contemporâneo em Administração, Rio de Janeiro, v. 2, n. 3, p. 42-58, set./dez. 2008.

SARTORI, A. G. O. Produção de indicadores de desempenho em sustentabilidade para o setor de etanol de cana-de-açúcar do estado de São Paulo. 2017. Tese (Doutorado em Ciências Engenharia Ambiental) Universidade de São Carlos, São Carlos, 2017. Disponível em: https://teses.usp.br/teses/disponiveis/18/18139/tde-30102017-

144648/publico/TeseAndreGiovaniniDeOliveiraSartori.pdf. Acesso em: 30 nov. 2019.

SILVA, V. S; GARCIA, C. A.; SILVA, C. M. O destino do bagaço da cana-deaçúcar: um estudo a partir das agroindústrias sucroalcooleiras do Paraná. Revista em Agronegócios e Meio Ambiente, Maringá, v.3, n.1, p. 59-76, jan./abr. 2010.

SILVA, G. H. P.; NEVES, L. F.; GEORGES, M. R. R. Estudo bibliométrico sobre indicadores de sustentabilidade: trabalhos desenvolvidos e disponibilizados na Biblioteca Digital Brasileira de Teses e Dissertações. In: ENCONTRO INTERNACIONAL SOBRE GESTÃO AMBIENTAL E MEIO AMBIENTE. 20., São Paulo. Anais [...] São Paulo, 2018.

SMALL, $H$. On the shoulders of Robert Merton: towards a normative theory of citation. Scientometrics, v. 60, n.1, p. 71-79, 2004.

SOUZA, J. G. Desenvolvimento: como compreender e mensurar. Curitiba: Appris, 2018.

VAN BELLEN, H. M. Indicadores de Sustentabilidade: uma análise comparativa. 2. ed. São Paulo: FGV, 2008. 